Check for updates

Cite this: RSC Adv., 2017, 7, 54772

\title{
First-principles study of a new structure and oxidation mechanism of $\mathrm{Pt}_{3} \mathrm{Zr}$
}

\author{
Yong Pan, (D)* Shuanglun Wang, Linhu Jia and Xi Zhang \\ Zirconia $\left(\mathrm{ZrO}_{2}\right)$-metal interfaces are interesting for solid oxide fuel cells. Although the oxidation of $\mathrm{Pt}_{3} \mathrm{Zr}$ \\ provides a new route for the formation of $\mathrm{ZrO}_{2}-\mathrm{Pt}$ interfaces, the crystal structure of $\mathrm{Pt}_{3} \mathrm{Zr}$ remains \\ controversial and the oxidation mechanism of $\mathrm{Pt}_{3} \mathrm{Zr}$ is unclear. To solve these problems, we use first- \\ principles calculations to explore the crystal structure of $\mathrm{Pt}_{3} \mathrm{Zr}$. We demonstrate a stable structure of $\mathrm{Pt}_{3} \mathrm{Zr}$ \\ based on phonon dispersion. Importantly, two new $\mathrm{Pt}_{3} \mathrm{Zr}$ structures, $\mathrm{Ti}_{3} \mathrm{Pt}$-type $(\mathrm{Pm} \overline{\mathrm{B}} \mathrm{m})$ and $\mathrm{Fe}_{3} \mathrm{Al}$-type \\ $(F m \overline{3} \mathrm{~m})$, are predicted. To study the oxidation mechanism, two possible doped models are considered. The \\ calculated results show that the $\mathrm{O}$ atom prefers to occupy the tetrahedral interstitial site (TI) in comparison \\ to the octahedral interstitial site (OI). We find that the oxidizing capacity of the FesAl-type cubic structure is \\ stronger than that of other structures. In particular, we predict that $\mathrm{Pt}_{3} \mathrm{Zr}$ exhibits better oxidation capacity \\ in comparison to other metals because of the strong localized hybridization between $\mathrm{Zr}$ and $\mathrm{O}$.
}

Received 13th October 2017 Accepted 25th November 2017

DOI: 10.1039/c7ra11299h

rsc.li/rsc-advances found that $\mathrm{Pt}_{3} \mathrm{Zr}$ belongs to a $\mathrm{Ni}_{3}$ Ti-type hexagonal structure, ${ }^{26}$ which is different from the previous viewpoint. As a result, the nature of oxidation mechanism of $\mathrm{Pt}_{3} \mathrm{Zr}$ is unclear.

To explore the catalytic activity of $\mathrm{Pt}_{3} \mathrm{Zr}$ and improve the formation of $\mathrm{ZrO}_{2}-\mathrm{Pt}$ interface, in our works, we investigate the crystal structure and oxidation mechanism of $\mathrm{Pt}_{3} \mathrm{Zr}$ by using the first-principles calculations. According to the structural feature, we predict two possible cubic structures. Importantly, the structural stability of $\mathrm{Pt}_{3} \mathrm{Zr}$ is estimated by the formation enthalpy and phonon dispersion. To examine the oxidation mechanism and oxidation capacity of $\mathrm{Pt}_{3} \mathrm{Zr}$, we calculate and compare the oxygen doped formation energy between $\mathrm{O}$-doped $\mathrm{Pt}_{3} \mathrm{Zr}$ and many metals. In particular, we examine the possible adsorption site of $\mathrm{Pt}_{3} \mathrm{Zr}$. Finally, we predict that $\mathrm{Pt}_{3} \mathrm{Zr}$ shows better oxidation capacity in comparison to many metals.

\section{Model and methods}

To explore the oxidation mechanism, we firstly study the crystal structure of $\mathrm{Pt}_{3} \mathrm{Zr}$. To our knowledge, one is that $\mathrm{Pt}_{3} \mathrm{Zr}$ is a Ni${ }_{3} \mathrm{Ti}^{-}$ type hexagonal structure with space group of $P 6_{3} / \mathrm{mmc}$. The lattice parameters of hexagonal structure are $a=5.653 \AA$ and $c=9.347 \AA$, respectively. ${ }^{24}$ Another is that $\mathrm{Pt}_{3} \mathrm{Zr}$ belongs to the $\mathrm{Au}_{3} \mathrm{Cu}$-type cubic structure with space group of $P m \overline{3} m$, and the lattice parameter is $a=4.051 \AA .^{26}$ In comparison to hexagonal structure, we suggest that $\mathrm{Pt}_{3} \mathrm{Zr}$ with cubic structure can promote the oxidation of $\mathrm{Pt}_{3} \mathrm{Zr}$ because of the localized hybridization between oxygen and $\mathrm{Pt}_{3} \mathrm{Zr}$. Therefore, we further design two possible structures: $\mathrm{Ti}_{3}$ Pt-type with cubic structure and $\mathrm{Fe}_{3} \mathrm{Al}$-type with cubic structure, respectively. The structural models of $\mathrm{Pt}_{3} \mathrm{Zr}$ are shown in Fig. 1.
School of Materials Science and Engineering, Southwest Petroleum University, Chengdu 610500, China. E-mail: panyong10@mails.jlu.edu.cn; Fax: +86-02883037406; Tel: +86-028-83037401 


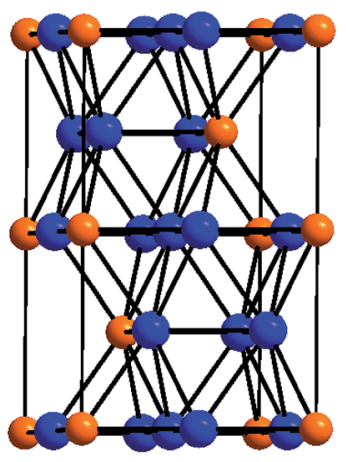

(a)

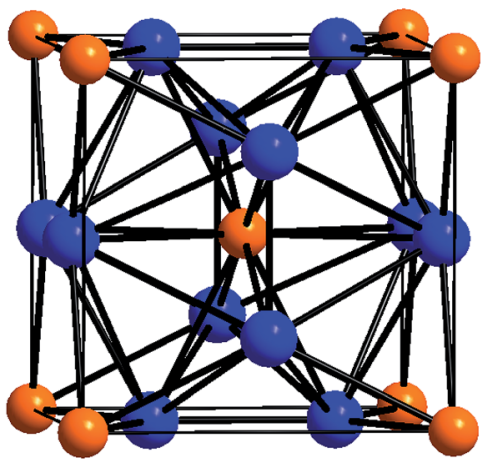

(c)

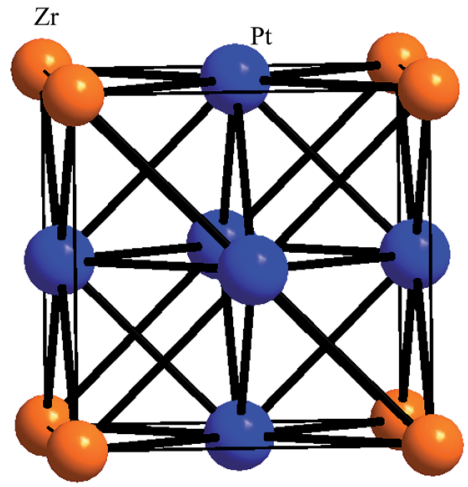

(b)

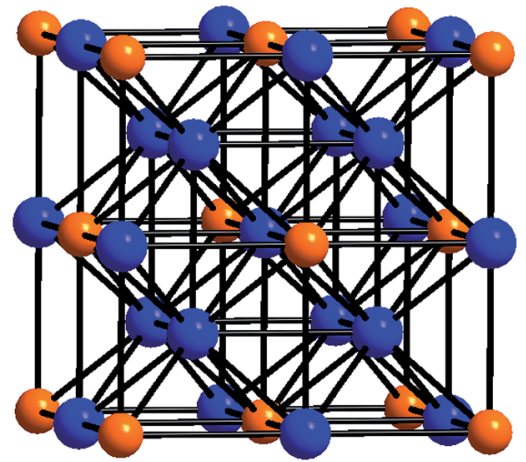

(d)

Fig. 1 Structural model of $\mathrm{Pt}_{3} \mathrm{Zr}$, (a) $\mathrm{Ni}_{3} \mathrm{Ti}$-type with hexagonal structure, (b) $\mathrm{Au}_{3} \mathrm{Cu}$-type with cubic structure, (c) Ti ${ }_{3} \mathrm{Pt}$-type with cubic structure and (d) $\mathrm{Fe}_{3} \mathrm{Al}$-type with cubic structure, respectively.

In this paper, the total energy, structural information, electronic structure and chemical bonding of $\mathrm{Pt}_{3} \mathrm{Zr}$ and O-doped $\mathrm{Pt}_{3} \mathrm{Zr}$ were calculated by using the first-principles calculations, as implemented in the CASTEP code. ${ }^{27}$ The exchangecorrelation-functional was calculated by using the generalized gradient approximation (GGA) within PW91 functional. ${ }^{28,29}$ To treat the interaction between electrons and the ions, the atomic configurations of $\mathrm{O}, \mathrm{Pt}$ and $\mathrm{Zr}$ were $2 \mathrm{~s}^{2} 2 \mathrm{p}^{4}, 5 \mathrm{p}^{6} 5 \mathrm{~d}^{9} 6 \mathrm{~s}^{1}$ and $4 \mathrm{p}^{6} 4 \mathrm{~d}^{2} 5 \mathrm{~s}^{2}$, respectively. Based on the convergence test, the plane-wave basis set for electron wave function with cutoff energy of $400 \mathrm{eV}$ was used. The $k$-point grids of $10 \times 10 \times 5$ for $\mathrm{Ni}_{3}$ Ti-type structure, $12 \times 12 \times 12$ for $\mathrm{Au}_{3} \mathrm{Cu}$-type structure, 10 $\times 10 \times 10$ for $\mathrm{Ti}_{3} \mathrm{Pt}$-type structure, $11 \times 11 \times 11$ for $\mathrm{Fe}_{3} \mathrm{Al}$-type structure, $14 \times 14 \times 8$ for $\mathrm{Zr}$ and $17 \times 17 \times 17$ for Pt were treated, respectively. To examine the dynamically stable, the phonon calculation was carried out by using the supercell method within the PHONON code. ${ }^{30}$

\section{Results and discussions}

\subsection{Structural prediction}

The structural stability of $\mathrm{Pt}_{3} \mathrm{Zr}$ is measured by the formation enthalpy and phonon dispersion, respectively. The equation of formation enthalpy $(\Delta H)$ is given by:

$$
\Delta H=E_{\mathrm{Pt}_{3} \mathrm{Zr}}-3 E_{\mathrm{Pt}}-E_{\mathrm{Zr}}
$$

where $E_{\mathrm{Pt} Z \mathrm{Zr}}, E_{\mathrm{Pt}}$ and $E_{\mathrm{Zr}}$ are the total energy of $\mathrm{Pt}_{3} \mathrm{Zr}$, isolated Pt atom and isolated $\mathrm{Zr}$ atom, respectively.

Table 1 lists the calculated lattice parameters, density, and formation enthalpy of $\mathrm{Pt}_{3} \mathrm{Zr}$ with four structures. It can be seen that these structures are thermodynamically stable at the ground state because the calculated formation enthalpy of these structures is smaller than zero. Our predicted two structures ( $\mathrm{Ti}_{3} \mathrm{Pt}$-type and $\mathrm{Fe}_{3} \mathrm{Al}$-type) are also thermodynamically stable. Importantly, the calculated formation enthalpy of $\mathrm{Ni}_{3} \mathrm{Ti}$-type structure is $-8.188 \mathrm{eV}$ per atom, which is smaller than that of $\mathrm{Au}_{3} \mathrm{Cu}$-type structure. The slight difference implies that external condition is easy to result in phase transition from $\mathrm{Ni}_{3} \mathrm{Ti}$-type structure to $\mathrm{Au}_{3} \mathrm{Cu}$-type structure. This result is similar to the Fairbank's viewpoint. ${ }^{24}$

Table 1 Calculated equilibrium lattice parameters, a-axis and $c$-axis (A), density, $\rho\left(\mathrm{g} \mathrm{cm}^{-3}\right)$ and formation enthalpy, $\Delta H$ (eV per atom) of $\mathrm{Pt}_{3} \mathrm{Zr}$

\begin{tabular}{llllll}
\hline Structure & Method & $a$ & $c$ & $\rho$ & $\Delta H$ \\
\hline $\mathrm{Ni}_{3}$ Ti-type & GGA & 5.742 & 9.398 & 16.75 & -8.188 \\
& Exp $^{24}$ & 5.653 & 9.347 & & \\
$\mathrm{Au}_{3}$ Cu-type & GGA & 4.061 & & 17.77 & -8.178 \\
& Theo $^{25}$ & 3.980 & & & \\
& Exp $^{26}$ & 4.051 & & & \\
$\mathrm{Ti}_{3}$ Pt-type & GGA & 5.198 & & 16.00 & -7.918 \\
$\mathrm{Fe}_{3}$ Al-type & GGA & 6.513 & & 16.26 & -7.871
\end{tabular}


In addition to thermodynamically stable, the dynamically stable of $\mathrm{Pt}_{3} \mathrm{Zr}$ should examine follow. To study the dynamically stable, Fig. 2 displays the calculated phonon dispersion curves of $\mathrm{Pt}_{3} \mathrm{Zr}$ with four structures. It is clear that $\mathrm{Pt}_{3} \mathrm{Zr}$ with $\mathrm{Ni}_{3}$ Ti-type structure is a dynamically unstable because the imaginary phonon frequency is observed in this structure. However, we find that there is no imaginary phonon frequency in $\mathrm{Au}_{3} \mathrm{Cu}$-type structure, indicating that this structure is a dynamically stable at the ground state. Based on the first-principles calculations, we demonstrate the Stalick's viewpoint. Importantly, we predict two new $\mathrm{Pt}_{3} \mathrm{Zr}$ structures ( $\mathrm{Ti}_{3} \mathrm{Pt}$-type and $\mathrm{Fe}_{3} \mathrm{Al}$-type) because no imaginary phonon frequencies are found in these structures.

To further insight into the nature of dynamically stable, Fig. 3 shows the calculated phonon density of state (PhDOS) of $\mathrm{Pt}_{3} \mathrm{Zr}$ with four structures. It can be seen that negative frequencies are found in $\mathrm{Ni}_{3}$ Ti-type structure, indicating that this structure is a mechanically unstable at the ground state. The calculated PhDOS profile reveals that the mechanically unstable of $\mathrm{Ni}_{3}$ Ti-type is attributed to the vibration of $\mathrm{Pt}$ atom at low frequency region. However, $\mathrm{Au}_{3} \mathrm{Cu}$-type, $\mathrm{Ti}_{3}$ Pt-type and $\mathrm{Fe}_{3} \mathrm{Al}$-type structures are mechanically stable because no negative frequencies are observed in these structures. In particular, the whole low frequency model of $\mathrm{Au}_{3} \mathrm{Cu}$-type structure derives from the vibration of $\mathrm{Pt}$ atom and $\mathrm{Zr}$ atom. With increasing frequency, Zr's vibration plays an important role in thermodynamic properties. Therefore, it is concluded that the structural stability of $\mathrm{Pt}_{3} \mathrm{Zr}$ is markedly influenced by $\mathrm{Pt}-\mathrm{Zr}$ bond.

To further reveal the structural stability, the structural information of $\mathrm{Pt}_{3} \mathrm{Zr}$ is discussed. As listed in Table 1, the calculated lattice parameters of $\mathrm{Ni}_{3}$ Ti-type structure (space group: $P 6_{3} / \mathrm{mmc}$, no: 194) are $a=5.742 \AA$ and $c=9.398 \AA$, which are in good agreement with the experimental data. ${ }^{24}$ In this structure (see
Fig. 1(a)), the alternative Pt layer and Pt-Zr layer can be viewed along the $c$-axis. In particular, each $\mathrm{Zr}$ atom is surrounded by $4 \mathrm{Pt}$ atoms at $\mathrm{Pt}-\mathrm{Zr}$ layer. Therefore, Pt-Zr bond (2.601 $\AA$ ) can improve the structural stability of $\mathrm{Pt}_{3} \mathrm{Zr}$ with $\mathrm{Ni}_{3}$ Ti-type structure. However, the cohesive force between layers is determined by the bond strength of $\mathrm{Pt}-\mathrm{Pt}$ bond and part of Pt-Zr bond. In other words, Pt-Pt and Pt-Zr bonds play a key role in structural stability. The calculated bond length of Pt-Pt and Pt-Zr bonds is $2.924 \AA$ and $2.968 \AA$, respectively.

For $\mathrm{Au}_{3} \mathrm{Cu}$-type structure (see Fig. 1(b)), the calculated lattice parameter is $a=4.061 \AA$, which is in excellent agreement with the experimental data and theoretical results. ${ }^{25,26}$ Note that the symmetrical Pt-Zr bonds effectively improve it's structural stability. The calculated bond length of Pt-Zr bond is $2.871 \AA$, which is similar to the previous theoretical result. ${ }^{31}$ Note that the bond length of $\mathrm{Pt}-\mathrm{Zr}$ bond of $\mathrm{Au}_{3} \mathrm{Cu}$-type structure is slightly smaller than the corresponding bond for $\mathrm{Ni}_{3}$ Ti-type structure, indicating that the structural feature of the former can obviously improve the structural stability in comparison to the latter. Thus, we should consider the cubic structure to oxidize $\mathrm{Zr}$.

The calculated lattice parameter of $\mathrm{Ti}_{3} \mathrm{Pt}$-type and $\mathrm{Fe}_{3} \mathrm{Al}$-type structures is $a=5.198 \AA$ and $a=6.513 \AA$, respectively. From Fig. 1, $\mathrm{Ti}_{3}$ Pt-type structure is similar to $\mathrm{Nb}_{3}$ Si-type structure. In comparison to $\mathrm{Au}_{3} \mathrm{Cu}$-type structure, $\mathrm{Pt}$ atom in $\mathrm{Ti}_{3}$ Pt-type structure occurs migration from $(0.50,0,0.50)$ site to $(0.25,0$, $0.50)$ site. As a result, the variation of atomic position changes the localized hybridization between $\mathrm{Pt}$ and $\mathrm{Zr}$, which forms two different $\mathrm{Pt}-\mathrm{Zr}$ bonds. The calculated bond length of $\mathrm{Pt}-\mathrm{Zr}$ bond is $2.599 \AA$ and $2.906 \AA$, respectively. In particular, the atomic configuration can provide a large number of interstitial sites to adsorb oxygen. In addition, we find that the calculated lattice parameter of $\mathrm{Ti}_{3} \mathrm{Pt}$-type and $\mathrm{Fe}_{3} \mathrm{Al}$-type structures is larger than that of $\mathrm{Au}_{3} \mathrm{Cu}$-type structure.

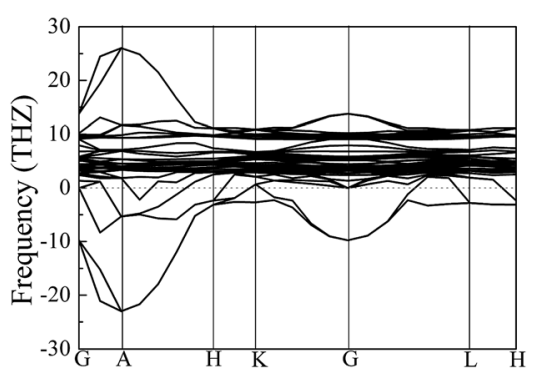

(a) $\mathrm{Ni}_{3}$ Ti-type

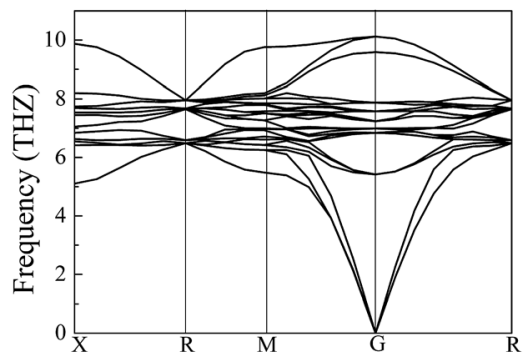

(c) $\mathrm{Ti}_{3}$ Pt-type

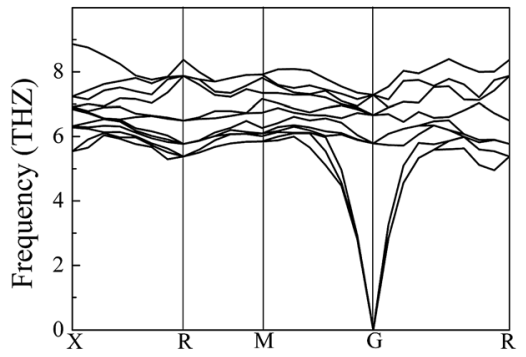

(b) $\mathrm{Au}_{3} \mathrm{Cu}$-type

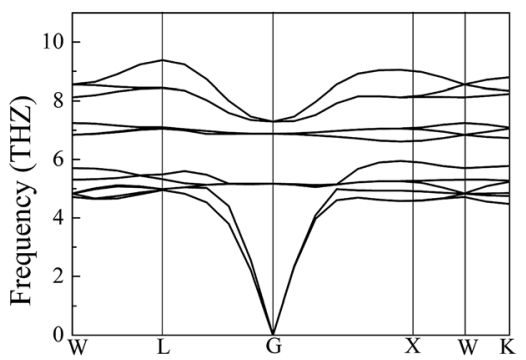

(d) $\mathrm{Fe}_{3} \mathrm{Al}$-type

Fig. 2 Calculated phonon dispersion curves of $\mathrm{Pt}_{3} \mathrm{Zr}$, (a) Ni ${ }_{3} \mathrm{Ti}$-type structure, (b) $\mathrm{Au}_{3} \mathrm{Cu}$-type structure, (c) Ti ${ }_{3} \mathrm{Pt}$-type structure and (d) Fe $\mathrm{Al}_{3}$-type structure, respectively. 

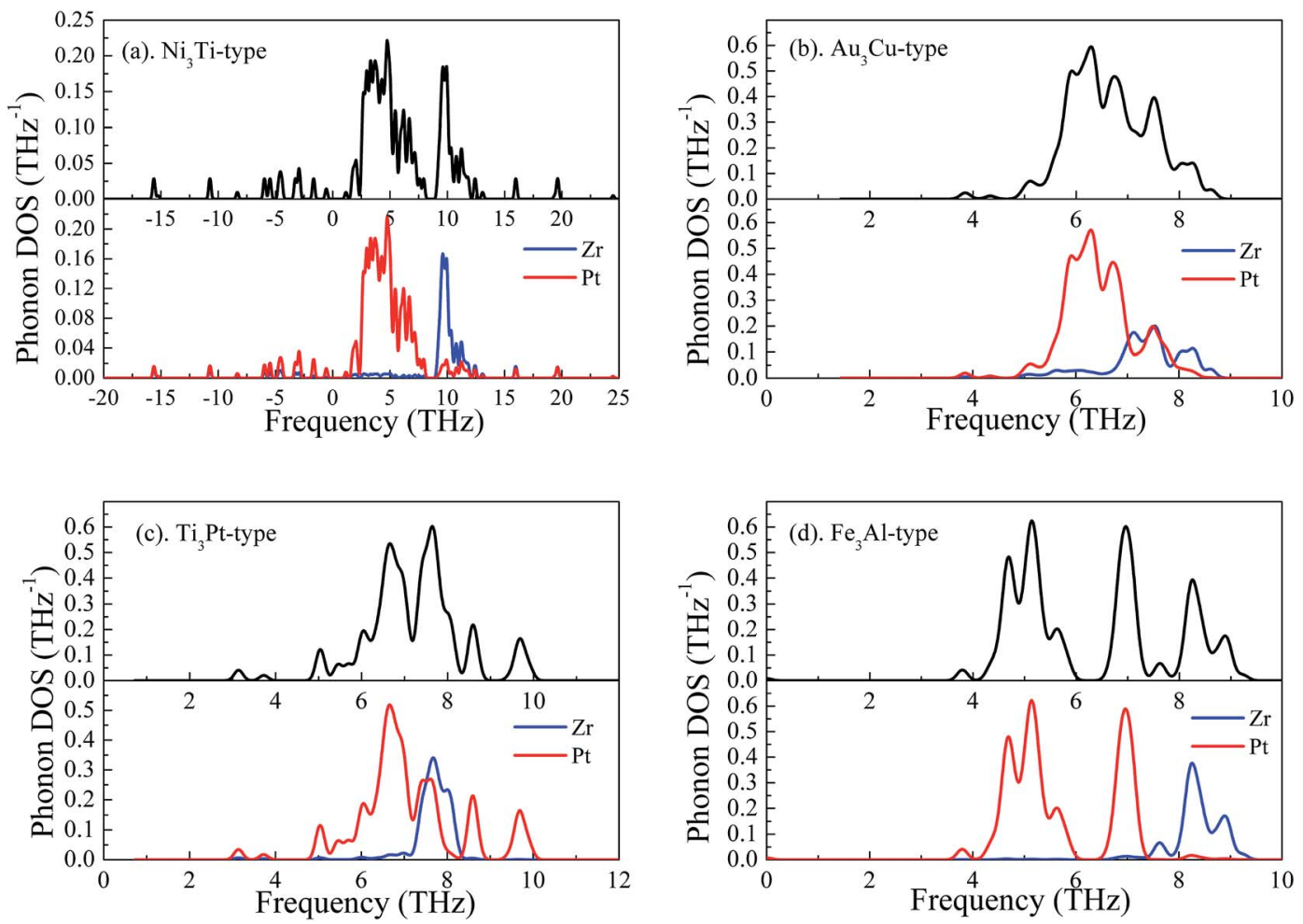

Fig. 3 Phonon density of state of $\mathrm{Pt}_{3} \mathrm{Zr}$, (a) Ni ${ }_{3} \mathrm{Ti}$-type structure, (b) $\mathrm{Au}_{3} \mathrm{Cu}$-type structure, (c) $\mathrm{Ti}_{3} \mathrm{Pt}$-type structure and (d) Fe ${ }_{3} \mathrm{Al}$-type structure, respectively.

For $\mathrm{Fe}_{3} \mathrm{Al}$-type structure, $\mathrm{Pt}$ atom migrates from $(0.50,0,0.50)$ site to $(0.25,0.25,0.25)$ site. Each Pt atom is surrounded by $4 \mathrm{Zr}$ atoms and $8 \mathrm{Pt}$ atoms. The calculated bond length of $\mathrm{Pt}-\mathrm{Zr}$ bond is $2.820 \AA$. Importantly, the network $\mathrm{Pt}-\mathrm{Zr}$ bonds can improve the structural stability of $\mathrm{Pt}_{3} \mathrm{Zr}$.
To reveal the nature of chemical bonding, Fig. 4 shows the calculated density of state (DOS) of $\mathrm{Pt}_{3} \mathrm{Zr}$ with four structures. We can see that the DOS profile of $\mathrm{Pt}_{3} \mathrm{Zr}$ is composed of $\mathrm{Pt}-5 \mathrm{~d}$ state and $\mathrm{Zr}-4 \mathrm{~d}$ state. The strong localized hybridization between $\mathrm{Pt}$ and $\mathrm{Zr}$ forms the $\mathrm{Pt}-\mathrm{Zr}$ bond. It is worth noticing
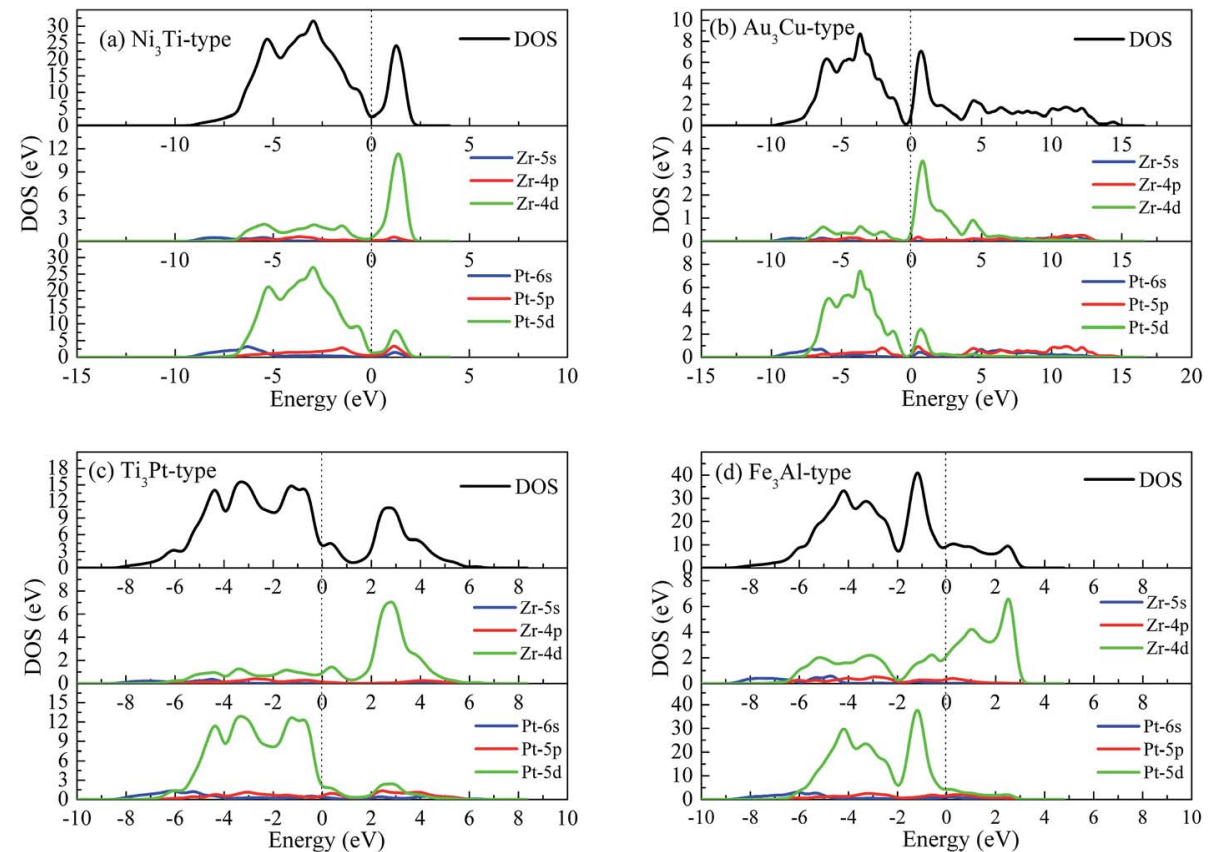

Fig. 4 Total and partial density of state (DOS) of $\mathrm{Pt}_{3} \mathrm{Zr}$, (a) Ni $\mathrm{Ni}_{3}$-type structure, (b) $\mathrm{Au}_{3} \mathrm{Cu}$-type structure, (c) $\mathrm{Ti}_{3} \mathrm{Pt}$-type structure and (d) Fe $\mathrm{A}_{3} \mathrm{Al}-$ type structure, respectively. 
that the DOS profile of $\mathrm{Ni}_{3}$ Ti-type structure is similar to $\mathrm{Au}_{3} \mathrm{Cu}$ type structure. From Fig. 4, there is a deep valley near Fermi level $\left(E_{\mathrm{F}}\right)$, which separates the bonding state and antibonding state. For $\mathrm{Ti}_{3} \mathrm{Pt}$-type and $\mathrm{Fe}_{3} \mathrm{Al}$-type structures, however, the $\mathrm{Zr}$ PDOS profile right shifts from $E_{\mathrm{F}}$ to high energy region. That is to say, Pt's migration weakens the localized hybridization between Pt and Zr. As a result, Pt-Pt bond plays an important role in structural stability, particularly for catalytic properties.

\subsection{Oxidation mechanism}

We suggest that the formation of $\mathrm{ZrO}_{2}-\mathrm{Pt}$ interface strongly depends on the interaction between $\mathrm{Pt}_{3} \mathrm{Zr}$ and $\mathrm{O}$ atom. To examine the formation of $\mathrm{ZrO}_{2}-\mathrm{Pt}$ interface, we calculate the oxygen doped formation energy of O-doped $\mathrm{Pt}_{3} \mathrm{Zr}$. In particular, we discuss and analyze the chemical bonding of O-doped $\mathrm{Pt}_{3} \mathrm{Zr}$ to reveal the formation of $\mathrm{ZrO}_{2}-\mathrm{Pt}$ interface. It must be mentioned that the formation of $\mathrm{ZrO}_{2}$ film is related to the interstice radius of $\mathrm{Pt}_{3} \mathrm{Zr}$, which is determined by the atomic configuration of $\mathrm{Pt}_{3} \mathrm{Zr}$. Therefore, it is necessary to insight into the oxidation mechanism of $\mathrm{Pt}_{3} \mathrm{Zr}$.

According to the first-principles calculations, we consider the oxidation behavior of three stable $\mathrm{Pt}_{3} \mathrm{Zr}$ structures: $\mathrm{Au}_{3} \mathrm{Cu}$ type, $\mathrm{Ti}_{3}$ Pt-type and $\mathrm{Fe}_{3} \mathrm{Al}$-type, respectively. To reveal the oxidation mechanism, we design the possible interstice models: tetrahedral interstice site (TI) and octahedral interstice site (OI), respectively. Oxygen mechanism of $\mathrm{Pt}_{3} \mathrm{Zr}$ is measured by the oxygen doped formation energy $\left(E_{\mathrm{ad}}\right)$, which is given by:

$$
E_{\mathrm{ad}}=E_{\mathrm{Pt}_{3} \mathrm{Zr}}^{\mathrm{O}}-E_{\mathrm{Pt}_{3} \mathrm{Zr}}-\mu_{\mathrm{O}}
$$

where $E_{\mathrm{Pt}_{3} \mathrm{Zr}}^{\mathrm{O}}$ and $E_{\mathrm{Pt}_{3} \mathrm{Zr}}$ are the total energy of O-doped $\mathrm{Pt}_{3} \mathrm{Zr}$ and parent $\mathrm{Pt}_{3} \mathrm{Zr}$ at the ground state, respectively. $\mu_{\mathrm{O}}$ is the chemical potential of $\mathrm{O}$ atom. Generally, the negative oxygen doped formation energy indicates the thermodynamically stable at the ground state.

To explore the catalytic activity of $\mathrm{Pt}_{3} \mathrm{Zr}$, we calculate and compare the capacity of oxygen between $\mathrm{Pt}_{3} \mathrm{Zr}$ and many metals. Firstly, we explore the oxidation mechanism of $\mathrm{Pt}_{3} \mathrm{Zr}$. From Fig. 1, $\mathrm{Au}_{3} \mathrm{Cu}$-type is a typical cubic structure. Therefore, we design two possible occupied sites: TI site and OI site, respectively. However, the structural feature of $\mathrm{Ti}_{3} \mathrm{Pt}$-type structure is more complex than that of $\mathrm{Au}_{3} \mathrm{Cu}$-type structure. According to the structural feature, we design two different OI sites and one TI site. Although the doped model of $\mathrm{Fe}_{3} \mathrm{Al}$-type structure is similar to $\mathrm{Au}_{3} \mathrm{Cu}$-type structure, the atomic interaction of the former is stronger than the latter. That is to say, $\mathrm{Fe}_{3} \mathrm{Al}$-type structure is easily to adsorb a large number of oxygen.

Fig. 5 shows the calculated oxygen doped formation energy of O-doped $\mathrm{Pt}_{3} \mathrm{Zr}$ and many metals. We can conclude that TI model is more thermodynamically stable than that of OI model because the calculated oxygen doped formation energy of the former is lower than the latter. This discrepancy is attributed to the localized hybridization between $\mathrm{O}$ and $\mathrm{Zr}$. For $\mathrm{Pt}_{3} \mathrm{Zr}$, TI site can effectively improve the charge interaction between $\mathrm{Zr}$ and $\mathrm{O}$, which forms the $\mathrm{Zr}-\mathrm{O}$ bond. In particular, $\mathrm{O}$ atom prefers to occupy the TI site of $\mathrm{Fe}_{3} \mathrm{Al}$-type structure in comparison to other structures. Therefore, we can adjust the crystal structure of

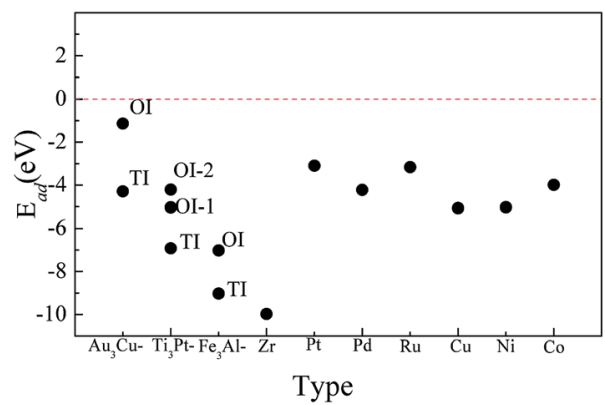

Fig. 5 Calculated oxygen adsorption energy of O-doped $\mathrm{Pt}_{3} \mathrm{Zr}$ at tetrahedral interstice site (TI) and octahedral interstice site (OI), together with many metals.

$\mathrm{Pt}_{3} \mathrm{Zr}$ to promote the formation of $\mathrm{ZrO}_{2}$. In particular, the calculated oxygen doped formation energy of $\mathrm{Fe}_{3} \mathrm{Al}$-type with $\mathrm{TI}$ site is about $-9.029 \mathrm{eV}$, which is smaller than that of other structures. This result indicates that $\mathrm{Pt}_{3} \mathrm{Zr}$ with $\mathrm{Fe}_{3} \mathrm{Al}$-type structure shows the better catalytic activity in comparison to other structures. This reason is attributed to the atomic configuration of $\mathrm{Pt}_{3} \mathrm{Zr}$.

As we know, many metals such as $\mathrm{Pt}, \mathrm{Cu}$, Ni and Co etc. are important parts of solid oxide fuel cells. ${ }^{32-35}$ To estimate the catalytic activity of $\mathrm{Pt}_{3} \mathrm{Zr}$, we compare the oxygen doped formation energy between $\mathrm{Pt}_{3} \mathrm{Zr}$ and many metals. As shown in Fig. 5, the calculated oxygen doped formation energy of metal $\mathrm{Zr}$ is $-10.068 \mathrm{eV}$, which is smaller than that of $\mathrm{Pt}_{3} \mathrm{Zr}$. This result indicates that metal $\mathrm{Zr}$ shows better oxidation capacity in comparison to $\mathrm{Pt}_{3} \mathrm{Zr}$. This is why $\mathrm{ZrO}_{2}$ has been widely investigated over the last years. Importantly, although the oxygen doped formation energy of $\mathrm{Pt}_{3} \mathrm{Zr}$ is larger than that of metal $\mathrm{Zr}$, the oxygen doped formation energy of $\mathrm{Pt}_{3} \mathrm{Zr}$ is smaller than that of other metals (see Fig. 5). The calculated electronic structure shows that the better oxidation capacity of $\mathrm{Pt}_{3} \mathrm{Zr}$ derives from the strong localized hybridization between $\mathrm{O}$ and metal $\mathrm{Zr}$. As mentioned above, we can predict that $\mathrm{Pt}_{3} \mathrm{Zr}$ is expected to have better catalytic activity in comparison to other metals.

To reveal the nature of the oxidation mechanism, we further analyze the chemical bonding of O-doped $\mathrm{Pt}_{3} \mathrm{Zr}$. The firstprinciple calculations show that the bond length of $\mathrm{Zr}-\mathrm{O}$ bond for $\mathrm{Au}_{3} \mathrm{Cu}$-type structure and $\mathrm{Ti}_{3} \mathrm{Pt}$-type structure is $2.026 \AA$ and $2.014 \AA$, respectively, which are smaller than the corresponding $\mathrm{Zr}-\mathrm{O}$ bond (2.05 $⿱$ $)$ of $\mathrm{ZrO}_{2} \cdot{ }^{36,37}$ However, the calculated bond length of $\mathrm{Zr}-\mathrm{O}$ bond of $\mathrm{Fe}_{3} \mathrm{Al}$-type structure is 2.076 $\AA$, which is close to the bond length of $\mathrm{Zr}-\mathrm{O}$ bond for $\mathrm{ZrO}_{2}$. On the other hand, the calculated electronic localization density shows that there is a strong localized hybridization between $\mathrm{Pt}$ and $\mathrm{O}$ for $\mathrm{Au}_{3} \mathrm{Cu}$-type structure. The calculated bond length of Pt-O bond is $2.117 \AA$ A. However, Pt-O antibonding state in $\mathrm{Ti}_{3} \mathrm{Pt}$ type and $\mathrm{Fe}_{3} \mathrm{Al}$-type structures is found. In other words, $\mathrm{Ti}_{3} \mathrm{Pt}-$ type and $\mathrm{Fe}_{3} \mathrm{Al}$-type structures are beneficial to the formation of $\mathrm{ZrO}_{2}$. The oxidation mechanism of $\mathrm{Pt}_{3} \mathrm{Zr}$ with three structures is shown in Fig. 6. As mentioned above, we predict that $\mathrm{Pt}_{3} \mathrm{Zr}$ with $\mathrm{Fe}_{3} \mathrm{Al}$-type structure is beneficial to the formation of $\mathrm{ZrO}_{2}$.

To gain insight the nature of oxidation behavior, Fig. 7 shows the calculated DOS of O-doped $\mathrm{Pt}_{3} \mathrm{Zr}$ with three structures. We 


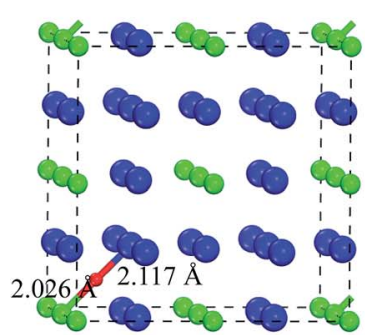

(a)

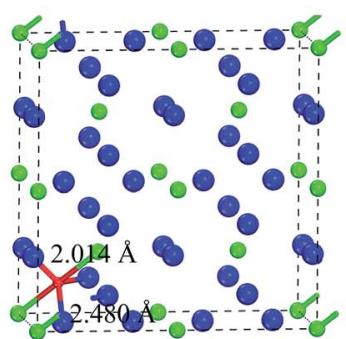

(b)

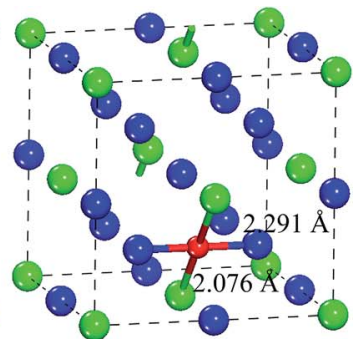

(c)

Fig. 6 Oxygen adsorption mechanism of $\mathrm{Pt}{ }_{3} \mathrm{Zr}$, (a) $\mathrm{Au}_{3} \mathrm{Cu}$-type structure, (b) Ti ${ }_{3} \mathrm{Pt}$-type structure and (c) Fe $\mathrm{Fe}_{3} \mathrm{Al}$-type structure, respectively.
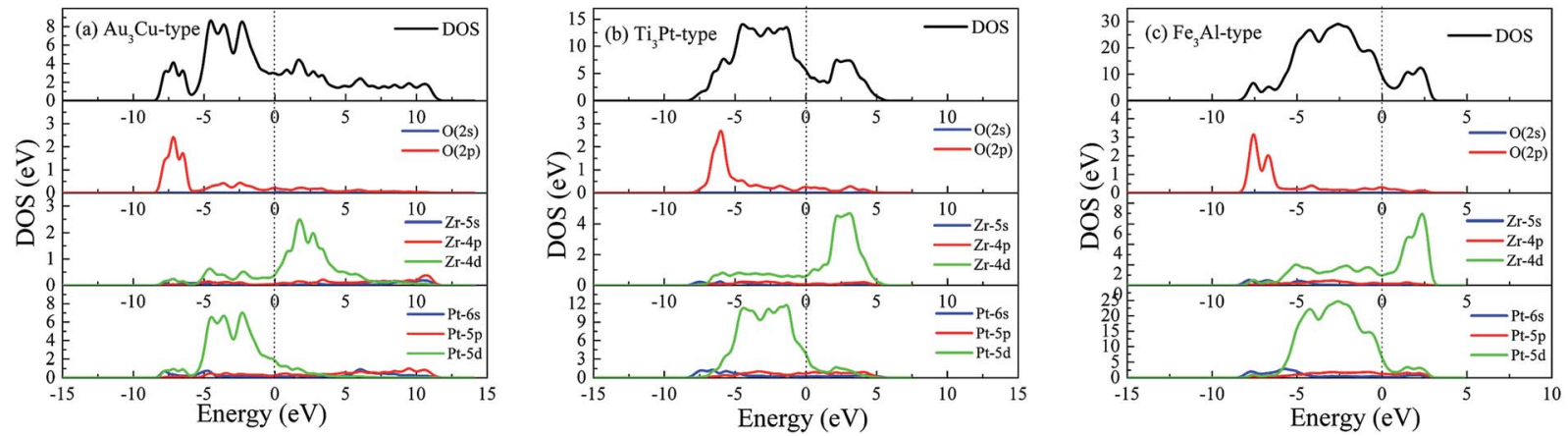

Fig. 7 Total and partial density of state (DOS) of O-doped $\mathrm{Pt}_{3} \mathrm{Zr}$, (a) $\mathrm{Au}_{3} \mathrm{Cu}$-type structure, (b) Ti ${ }_{3} \mathrm{Pt}$-type structure and (c) Fe ${ }_{3} \mathrm{Al}$-type structure, respectively.

observe that the DOS profile of $\mathrm{Pt}_{3} \mathrm{Zr}$ is mainly contributed by Pt$5 \mathrm{~d}$ state and $\mathrm{Zr}-4 \mathrm{~d}$ state. The strong localized hybridization between Pt and $\mathrm{Zr}$ forms the Pt-Zr bond. However, oxygen addition can improve the charge equilibrium between $\mathrm{Pt}$ and $\mathrm{Zr}$. As shown in Fig. 7, we can see that the charge interaction between $\mathrm{O}$ and $\mathrm{Zr}$ forms the $\mathrm{Zr}-\mathrm{O}$ bond, which demonstrates the existence of $\mathrm{Zr}-\mathrm{O}$ bond.

\section{Conclusions}

In summary, we apply first-principles calculations to study the crystal structure and oxidation mechanism of $\mathrm{Pt}_{3} \mathrm{Zr}$. To explore the stable structure, we calculate the formation enthalpy, phonon dispersion, lattice parameters and electronic structure of $\mathrm{Pt}_{3} \mathrm{Zr}$. In addition, we predict two possible new $\mathrm{Pt}_{3} \mathrm{Zr}$ structures: $\mathrm{Ti}_{3} \mathrm{Pt}$-type (space group: $P m \overline{3} m$, no. 223 ) and $\mathrm{Fe}_{3} \mathrm{Al}$-type (space group: $F m \overline{3} m$, no. 225). To investigate the oxidation mechanism, we calculate the oxygen doped formation energy and chemical bonding of O-doped $\mathrm{Pt}_{3} \mathrm{Zr}$. In particular, we compare the oxygen doped formation energy of $\mathrm{Pt}_{3} \mathrm{Zr}$ and many metals.

The calculated results show that although $\mathrm{Pt}_{3} \mathrm{Zr}$ with hexagonal structure is more thermodynamically stable than that of cubic structure, hexagonal structure is a dynamically unstable at the ground state. The calculated oxygen doped formation energy of TI site is smaller than that of OI site. The calculated oxygen doped formation energy of $\mathrm{Pt}_{3} \mathrm{Zr}$ with $\mathrm{Fe}_{3} \mathrm{Al}-$ type structure is smaller than that of other structures. The calculated chemical bonding shows that $\mathrm{Pt}_{3} \mathrm{Zr}$ with $\mathrm{Fe}_{3} \mathrm{Al}$-type structure is easy to form the $\mathrm{ZrO}_{2}$ because of the formation of $\mathrm{Zr}-\mathrm{O}$ bond. In particular, the calculated oxygen doped formation energy of $\mathrm{Fe}_{3} \mathrm{Al}$-type with TI site is smaller than that of other metals, indicating that $\mathrm{Pt}_{3} \mathrm{Zr}$ shows the good catalytic activity in comparison to metals.

\section{Conflicts of interest}

There are no conflicts to declare.

\section{Acknowledgements}

This work is supported by grants from the Sichuan Provincial Colleges' Sate Key Laboratory of Oil and Gas Reservoir Project (X151517KCL36) and the national natural science foundation of China (No. 51267007). We acknowledge the help from Lady Yun Zheng.

\section{References}

1 H. Y. T. Chen, S. Tosoni and G. Pacchioni, ACS Catal., 2015, 5, 5486-5495.

2 L. M. Toscani, A. Raievich, M. C. Aantini, D. G. Lamas and S. A. Larrondo, J. Phys. Chem. C, 2016, 120, 24165-24175.

3 A. P. Kulkarni, S. Giddey and S. P. S. Badwal, J. Phys. Chem. C, 2016, 120, 15675-15683.

4 N. S. Yuzbasi, A. M. Kierzkowska, Q. Imtiaz, P. M. Abdala, A. Kurlov, J. L. M. Rupp and C. R. Muller, J. Phys. Chem. C, 2016, 120, 18977-18985. 
5 P. Li, X. Chen, X. Wang, J. Shao, G. Lin, H. Yang, Q. Yang and H. Chen, Energy Fuels, 2017, 31, 3979-3986.

6 A. Ganesan, M. Narayanasamy, K. Shunmugavel and I. J. Chinnappa, Int. J. Hydrogen Energy, 2016, 41, 8963-8977.

7 F. Menegazzo, M. Signoretto, D. Marchese, F. Pinna and M. Manzoli, J. Catal., 2015, 326, 1-8.

8 E. Ciftyurek, C. D. Mcmillen, K. Sabolsky and E. M. Sabolsky, Sens. Actuators, B, 2015, 207, 206-215.

9 J. Ftouni, A. M. Murillo, A. Goryachev, J. P. Hofmann, E. J. M. Hensen, L. Lu, C. J. Kiely, P. C. A. Bruijnincx and B. M. Weckhuysen, ACS Catal., 2016, 6, 5462-5472.

10 F. Giannici, G. Canu, M. Gambino, A. Longo, M. Salome, M. Viviani and A. Martorana, Chem. Mater., 2015, 27, 27632766.

11 M. Kuzminska, T. V. Kovalchuk, R. Backov and R. M. Gaigneaux, J. Catal., 2014, 320, 1-8.

12 S. Grieshammer, J. Phys. Chem. C, 2017, 121, 15078-15084.

13 H. H. Li, S. Y. Ma, Q. Q. Fu, X. J. Liu, L. Wu and S. H. Yu, J. Am. Ceram. Soc., 2015, 137, 7862-7868.

14 Y. Sha, T. H. Yu, B. V. Merinov and W. A. Goddard, ACS Catal., 2014, 4, 1189-1197.

15 L. A. Avakyan, N. A. Kolpacheva, E. V. Paramonova, J. Singh, U. Hartfelder, J. A. V. Bokhoven and L. A. Bugaev, J. Phys. Chem. C, 2016, 120, 28057-28066.

16 H. Ostrom, H. Oberg, H. Xin, J. Larue, M. Beye, M. D. Angela and A. Nilsson, Science, 2015, 347, 978-982.

17 K. Ding, A. Gulec, A. M. Johnson, N. M. Schweitzer, G. D. Stucky, L. D. Marks and P. C. Stair, Science, 2015, 350, 189-192.

18 Y. Pan, C. Jin and P. Mao, J. Electron. Mater., 2017, 46, 66396645.

19 H. Sohn and U. Ozkan, Energy Fuels, 2016, 30, 5309-5322.

20 J. Durst, M. L. Haro, L. Dubau, M. Chatenet, Y. S. Olivier, L. Guetaz, P. B. Guillemaud and F. Maillard, J. Phys. Chem. Lett., 2014, 5, 434-439.

21 C. Zhang, S. Y. Hwang, A. Trout and Z. Peng, J. Am. Chem. Soc., 2014, 136, 7805-7808.
22 M. Antlanger, W. M. Schmölzer, J. Pavelec, F. Mittendorfer and J. Redinger, Phys. Rev. B: Condens. Matter Mater. Phys., 2012, 86, 035451.

23 J. J. Choi, W. M. Schmolzer, I. Valenti, P. Luches, F. Mittendorfer, J. Redinger, U. Diebold and M. Schmid, J. Phys. Chem. C, 2016, 120, 9920-9932.

24 G. B. Fairbank, C. J. Humphreys, A. Kelly and C. N. Jones, Intermetallics, 2000, 8, 1091-1100.

25 Y. Pan, Y. Lin, X. Wang, S. Chen, L. Wang, C. Tong and Z. Cao, J. Alloys Compd., 2015, 643, 49-55.

26 J. K. Stalick and R. M. Waterstrat, J. Alloys Compd., 2007, 430, 123-131.

27 M. D. Segall, P. J. D. Lindan, M. J. Probert, C. J. Pickard, P. J. Hasnip, S. J. Clark and M. C. Payne, J. Phys.: Condens. Matter, 2002, 14, 2717-2744.

28 J. P. Perdew and Y. Wang, Phys. Rev. B: Condens. Matter Mater. Phys., 1992, 45, 13244-13249.

29 G. Kresse and D. Joubert, Phys. Rev. B: Condens. Matter Mater. Phys., 1999, 59, 1758-1775.

30 S. Baroni, S. d. Gironcoli, A. D. Corso and P. Giannozzi, Rev. Mod. Phys., 2001, 73, 515.

31 Y. Pan, W. Guan, M. Wen, J. Zhang, C. Wang and Z. Tan, J. Alloys Compd., 2014, 585, 549-554.

32 Z. Zheng, C. Sun, R. Dai, S. Wang, X. Wu, X. An, Z. Wu and C. Xie, Energy Fuels, 2017, 31, 3091-3100.

33 M. Deutsch, F. Horvath, C. Knoll, D. Lager, C. G. Mayer, P. Weinberger and F. Winter, Energy Fuels, 2017, 31, 23242334 .

34 K. Nakao, T. Ishimoto and M. Koyama, J. Phys. Chem. C, 2016, 120, 16641-16648.

35 X. Yang, Y. Wang, M. Li, B. Sun, Y. Li and Y. Wang, Energy Fuels, 2016, 30, 2198-2203.

36 W. Piskorz, J. Grybos, F. Zasada, S. Cristol, J. F. Paul, A. Adamski and Z. Sojka, J. Phys. Chem. C, 2011, 115, 24274-24286.

37 M. Taddei, F. Costantino, V. Manuali and R. Vivani, Inorg. Chem., 2011, 50, 10835-10843. 